This union does not always take place, for we sometimes have a fracture remaining in the same state as the soft anchylosis before described (or the thickened ligament) for years, remaining moveable, and forming something similar to a joint. This deficiency in the formation of callus is in general attributed to a bad constitution, or to the part being much moved; but it does not appear to arise from either of these causes; for if the fracture is made compound, which has been done, the wound will heal well, and form a good callus; this then is a proof that the constitution was good. Motion does not appear to prevent it, for a dog that breaks his leg, and runs about with it loose and dangling in the streets, will have the bones as firmly united as if it was kept ever so quiet. In all the processes performed by nature, there are certain leading principles, which are followed by other operations in regular succession; if the first principle of action is stopped, or any other succeeding operation, it generally puts a stop to all which were to follow, there being a regular chain or connexion between the processes of nature to perform some work ; and if one of these is prevented, it generally stops all which were to follow, each depending on the other. This may be explained in what takes place in the descent of the testis. The descent of the testis is a natural operation of the animal economy at a certain period; when this process takes place, and the testis has descended, then commences the period for the closing of the tunica vaginalis; if by any accident the tunic is prevented from closing (as from a bit of intestine or omentum slipping into it) at the stated period, it then loses its disposition to perform such operation, and it remains ever after open. Thus it is in the different operations of nature, and this may perhaps be the cause of simple fractures not uniting sometimes; by some accident the leading operations may be destroyed or stopped, as, for instance, if the extravasated blood, which forms the beginning of callus, should lose its living principle, then by becoming extraneous it would give the stimulus for absorption. The extravasated blood may be absorbed as in an ecchymosis : it evidently loses its living principle in some cases. By losing its life it may not cogaulate, but give the stimulus for absorption; when absorbed, the other processes would not go on to unite the bones, but a new stimulus would be given, which would be to make a joint. I have lately met with a fractured thigh, in which the blood had been absorbed; on examining it I found a kind of granulation, shooting everywhere from the surface of the bone, which would, I think, have taken on the ossific disposition, and have performed the union. Thesewere not attended with pus ; therefore this is only necessary where the granulations are exposed, and perhaps intended as a covering. The extremities of the bones becoming enlarged, and the projecting parts of the bone rubbing against each other, give the stimulus for absorbing those parts, by which means the extremities of the bones become smooth, and covered with something similar to cartilage. The extremities of the bones are not ground by friction, for then we should find the matter which was ground.

The formation of a joint between the two ends of a fractured bone seldom happens; it is much more frequent for them to be united by soft anchylosis, that is, by a cartilaginous or membranous sub- stance, which will admit of some motion; and therefore, it is to be wished for in those cases where joints anchylose, but we know of no power to prevent ossification. The constitution, by being very much weakened, will prevent ossification, and even cause its absorption, but to bring it to such a state, perhaps, would not be prudent. These cases may be cured by making the fracture compound, when they are situated so as to admit of it; the exposing the extremities of the bones will give a stimulus, causing inflammation and granulation, when the callus will form in the granulations as in compound fractures, or become anchylosed, as in the exposure of joints. It may, perhaps, be necessary to saw off the ends of the bones to produce a greater inflammation.

A similar disposition take place in dislocations, as in cases where bones do not unite; the bones not being able to recover their situation, nature sets about making a new joint; if the head of the bone is situated against a bone, then the pressure causes an absorption, and makes a cavity to adapt itself to the head of the bone; a substance like a ligament is formed, and connects the bones together, secreting synovia and making a joint.

In this case two operations take place at the same time; the bone in contact ulcerates and the surrounding bone inflames, which causes it to thicken and raise itself round the head of the bone, forming an articulatory cavity. If the head of the bone is situated in soft parts, these adapt themselves to it in the same manner, making an articulatory cavity.

\section{CASE OF SHORTSIGHTEDNESS}

CURED BY OPERATION.

\section{TO THE EDITORS OF THE FROVINCIAL MEDI-} CAL AND SURGICAL JOURNAL.

Gentuemen,-The arduous and laborions pursuits of my profession have alone prevented me from contributing to your excellent Journal an earlier or a better production than the following, which, if you should think it worthy of insertion in your columns, is at your service.

\section{Your obedient servant, JAMES ADAMS.}

\section{7, New Broad Street, Sept. 1841.}

F Henry Stevens, æt. 17, a healthy-looking lad, marked by the small-pox, has light hair and gray irides, with rather more than usually dilated pupils. Association unusual; if the right eyelid be closed, the left eye remains in its natural central position; but if the right eyelid be suddenly raised, the right cornea will be found much inverted: if the right eyelid be left open, the right cornea is seen to move, gradually, to its natural central position, in order to correspond with the left ; if the left eyelid be closed, a similar result does not take place, the association being perfectly natural.

Position of both eyes perfectly natural. If an object be held close to the root of the nose, and the patient be desired to look at it, both corneæ are, at first, slightly and equally converged; but, as the effort to view the object with both eyes is 
increased, the left eye becomes more converged than the right, the cornea of which returns to its natural central position, and remains there. The power of inversion and eversion of the corneæ are equal and complete; with both eyes open, can see the letters of small print for a few seconds, if brought to a point within three inches of the eyes; and see to read very large print if within seven inches, but not beyond. His present employment is that of assisting to print oil floor-cloth, but he finds that it will be impossible to continue at the occupation, because he cannot see distinctly the marks * for joining the patterns, or tell the straightness of a line exceeding one yard in length. Has tried to follow the business of a wheelwright, but was obliged to abandon it on account of his not being able to see the figures of the rule, and inany other necessary parts of the work. Has also endeavoured to follow the trade of his father, namely, that of a tailor, but he can neither do fine needle-work, nor thread any needle less in size than a worsted one. His parents have taken much pains to teach him to read, and have procured for him books with very large type, but all to no purpose ; for if he endeavoured to fix his attention on the letters, they would become so obscured by a mist, as not to be recognised till the eyes have been rested; so that on any slight sxertion of the eyes they get dim and filled with tears, thus quickly depriving him of the power to eee anything distinctly.

If the left eye be open, while the right is closed, the sight is better than when both eyes are open; dimness, however, soon increases after exertion of the eye; its sight is best towards the nose; can see small print at three inches, and large print at seven.

With the right eye, unassisted by the left, the sight is much worse than if both eyes were open. He can just tell the difference between man and woman by their dress, but cannot see their features; cannot accurately tell the number of fingers that may be held before him, or see to distinguish the form of the largest printed letter, which, in order to examine, he holds at the distance of two inches from his eyes; the dimness of this eye, after very slight exertion, will increase to nearly perfect darkness; in general, the mist is less dense in a direction towards the shoulder.

He complains of much pain in the forehead, eyebrows, and temples, accompanied by a sense of soreness ; and that moderate bodily exertion, or application of the eyes to small objects, instantly excites the pains. If he looks at any small object for a few minutes, the sight not only becomes so dim as to leave him in perfect darkness, but the pains will have been produced in their severest degree, and will continue for an hour or more. The fits of pain are occasionally attended by attacks of sickness, giddiness, and general headache. Has been subject to these attacks ever since he had the small-pox; they have been more frequent in the summer than the winter.

History.-Previously to the age of nine years, his eyes were' perfectly healthy and natural; at nine years of age he was attacked by the smallpox, accompanied by severe inflammation of both eyes and intolerance of light, which lasted during many weeks.

* They are called pitch marks, and consist of thick wire points.
On his recovery, his eyes were much in the same condition as they are now, and they have continued thus ever since.

First operation.-May 10. Divided the right internal rectus muscle, which caused the right eye to slightly diverge, and its pupil to become largely dilated, but not to be deprived of the power of acting freely. It remained in this state for several hours after the operation.

12. Position of the right eye slightly divergent ; the left natural. Sight very much improved in the right eye : all objects look brighter and plainer; he can see objects at a greater distance than he has been accustomed. He has been using his eye to examine the lines of the pavement, the cracks in the floor between the boards, the markings of the tiles, \&c., all of which appear so very large and plain, and to quote his own words, he says that he "feels as. if he were in a new world, everything appears so strange;" can distinguish the lines of print, and the spaces between the letters; dimness deeply increases in the right eye after a moderate exertion. With both eyes open, sight is much better than it was before the operation; but he sees double at times, to the left side.

Treatment since the operation has been fomentation, and the close bandaging of the left eye.

17. Position of the right eye very divergent; of the left, natural. Sight of the right eye in every respect improved; can distinguish the features of different people; can tell accurately the number of fingers held up before him-in fact, he can recognize any object that may be presented to him, and can even read the letters of very large-sized print at the distance of six inches. The dimness after exertion of the eye still increases, but not so rapidly or to so severe a degree as it used to do.

Second operation.-Divided the right external rectus muscle, which caused the right eye to become straight, and the left slightly inverted.

19. Position of the right eye central ; left slightly inverted. Sight, with both eyes open, much better than he has ever known it to be; can read newspaper print with ease, at the distance of twelve inches, for a much longer time than before operation; (has not ventured to try the full extent of this improvement;) sight, in the right eye, remarkably improved; can read by it, easily, a print of twice the size of common newspaper print, at the distance of about nine inches. Dimness does not increase after moderate exertion, though he still sees best towards the right external canthus. He states that the sight in the left eye is very much improved since the operation on the right, for he can see further and plainer with it; also, that its dimness does not increase so quickly.

July 5. Position of both eyes perfectly natural, but the right eye is slightly more prominent than the left. Sight, with both eyes open, much improved ; can see to read moderate-sized print very distinctly, at the distance of one foot from his nose, and small print at a point situated nine inches from him ; dimness does not appear on moderate exertion. Sight in the loft eye improved; he can see with it when the right eye is shut as perfectly as if both eyes were open; he also sees equally well with it in all directions. Sight in the right eye not quite so good as in the left, or as with both eyes open; small print must be held at about seven inches from the nose; dimness does not increase after moderate exertion. 
As additional evidences of the improvement of H. S.'s vision with respect to distances, he states, that previously to cperation, he would be com$p$ lled to stand ciose under a house-clock if he wished to see the hour, and that at present he can see accurately to name its time from any part of the room in which the clock may be situated; h? also says that he has seen, since the last operation, the hands of a certain church clock, which is 80 situated with respect to one of the windows of the factory at which he is employed, that a person with good sight can tell its time; though previously to operation he could not discover even the position of the clock's dial; he adds, moreover, that since the day following the last operation, he has continued to work at his employment in the floorcloth manufactory, without on any occasion having missed the pitch or pattern marks, though previously to operation he would frequently do so by one inch or more.

The following circumstances relative to the position and motions of the eyes were now noticed.

Association, natural ; convergence, slight and equal at about six inches; repulsion in the right eye, and very slightly beyond its centre; inversion not complete in the right eye by one line, but more than complete in the left, by one quarter of the surface of the cornea ; eversion equal, but not complete by half a line.

He has been wonderfully relieved from pains about the brows, but still is subject to them over the right eye and right side of the nose. Has not had any attack of sickness since the first operation; he used to be subject to them two or three times a week, and their frequency had increased since his employment at the factory.

Third operation.-July 12. I divided the left external rectus muscle, which caused a complete inversion of the left cornea; the right eye remained in its central and natural position; after the operation he had no power of everting the left cornea beyond one line from its natural centre. If the right eyelid be closed, and the patient directed to look as much as possible to the left, the eversion. of the left cornea is not increased beyond one line outwards of its centre, though, if the eyelis be suddenly raised, the right cornea will be forind to be nearly completely inverted. If the let $t$ eyelid be closed, the left cornea will be found more inverted than when both eyelids are oper.

Sight, with both eyes open, improved; he can see to read a moderate-sized print at the distance of one and a quarter feet; sight in the right eye as before the last operation; sigh.t in the left eye improved, and equal to both eyes open. Sees slightly double, if he looks at an object situated on his left side.

He now complains of severe pain in the left eye, which is felt at the upper and outer part of the left edge of the cornea; it is only felt at the instant of closing the right eye.

August 3. Position of the right eye central, and that of the left eye slightly inverted. Wound nearly healed. The prominence of the right eye is yet more evident than that of the left. Sight, with both eyes open, slightly improved since last report; he can read t', se small print, " pearl," at the distance of nins: inches, and newspaper print at the distance of inore than a foot from him. If he holds small $r$,rint at the distance of three inches, (the distar ${ }_{\perp}$ ce he was compelled to hold it pre- viously to operation,) he cannot see it so distinctly as when held at about five or six inches, and to try to do so makes his eyes ache. He says that he can see to thread a very fine needle at the distance of seven inches. Sight in the left eye not quite equal to the sight experienced with both eyes open ; can see small print, " pearl," only at eight inches ; its dimness increases after moderate exertion, and he sees best towards the nose, so that the sight in this eye is, for the present, slightly the worse for the operation. Sight in the right eye not quite equal to the left; sees equally well with it in all directions ; small print, "pearl," is seen at seven inches, and dimness does not increase after exertion; the sight, in this eye, remains as before the last operation. He says that he can see to follow every branch of his business without the slightest inconvenience, but that he occasionally finds himself stooping over his work from habit, which he endeavours to correct, being now able to see to do any part of the work from the same distance as most other men.

He has occasionally pains of a shooting character about both temples, which are increased by a close day's work. The pain in the left eye has subsided ; association, active and central in the left; convergence, equal and full at three inches; repulsion of the right eye full to the centre; iriversion of the right eye just complete, but in the left more than complete by one quarter of its conical surface; eversion not complete in ihe right by fully one line, and in the left by n.early two lines.

Fourth operation.-9. Jivided the left internal rectus muscle, and bott, eyes became and remained perfectly straight.

September 1. The appearance, position, and association of 'nis eyes are perfectly natural. 'I'he eyeballs are, not in the least degree more prominent thar. natural, nor is one more prominent than the other, though both are somewhat fuller in arpearance than previously to operation, so that th's operations have caused an improvement in the appearance and expression of his eyes. Convergence full and equal at two inches; repulsion in the right eye more than central; inversion and eversion complete, and equal. Sight, with both eyes open, remarkably good; he can see to read small print, " pearl," at twelve inches, and a full sized print at about three feet. A day's close work does not cause the slightest inconvenience.

He saw, a few days since, Mr. Green's balloon more distinctly than he had ever seen it in his life; he even saw the ballast falling from the car; formerly, a balloon never appeared to him to be larger than the size of his head,-though other persons used to describe to him its immense proportions; he never recognized a car to a balloon till the late occasion.

He can see every object much more distinctly, and at a greater distance, with both eyes open, than by either singly; for instance, small print is distinctly seen at the distance of twelve inches, when both eyes are used, and at only eight or nine, if either eye alone be employed. Sight, in the left and right eyes, has much improved since the last operation, and its strength and clearness are now equally good in either.

The above case is here for the first time published complete, a portion of it only having been published in a letter, which I have recently addressed to Dr. R. Farre, and entitled, "A New 
Operation for Amaurosis, Impaired Vision, and Shortsightedness." The letter above alluded to contains a full account of the principles on which this case and others have been treated, and must therefore render their repetition here unnecessary. For the satisfaction of some of your readers, who may hesistate about performing operations on the muscles of undistorted eyes, where there is defect of sight, I beg to say, that in no one instance has the termination of any of my cases been attended by any incurable deformity.

\section{CASE OF A FEETUS}

VIABLE AT SIX MONTHS.

TO THE EDITORS OF THE PROVINCIAL MEDICAL AND SURGICAL, JOURNAL.

Gentlemen,-There is no question in medicolegal science more difficult, and none more interesting and important, than that of the exact limits of utero-gestation, that is, the longest and the shortest periods which a child may be carried in the womb, and yet survive. I think, therefore, that the following case, affording an example of as early a foetus proving to be viable as any that $I$ have ever heard of, may be interesting to your readers, and at any rate deserves to be put on record.

'The great difficulty in attesting the exact limits of gestation of course arises, first, from so few women comparatively becoming pregnant under circumstances that enable us to fix the time of conception ; and secondly, from the fact that of those few, so small a number are either willing or capable of giving a clear and satisfactory statement of those circumstances, or whose testimony is altogether worthy of credit. With regard to the case now presented, though for obvious reasons I cannot mention the name, yet I think the very lucid and candid statement of facts will speak for itself in a most satisfactory manner, and to it I will only add my full conviction, from a personal acquaintance with the patient, of its being entirely deserving of confidence.

'I'hat the question as to how early a foetus may be considered viable, is by no means settled, I think we have abundant proof in the conflicting evidence brought before the House of Lords, in the case of the Gairdner Peerage, and still more recently in the case of the Rev. Mr. Jardine, related in the Medico-Chirurgical Review. As this last case has been so much before the public, I will, as an introduction to my own case, mention its leading facts. The Rev. Mr. Jardine was the incumbent of a parish in Scotland; he married, and just six months after his marriage, Mrs. Jardine gave birth to an infant, which, though very small, still was strong enough to survive. The consequence of this was, that reports very prejudicial to the reputation of $\mathrm{Mr}$. and Mrs. Jardine were circulated. These were taken up and spread further by some persons who felt a personal hostility to the parties, and the parishioners insisted on the deposition of Mr. Jardine from his office of minister of the kirk. The cause was tried before the Ecclesiastical Court, and the parties were acquitted, the greater weight of medical evidence going to support the assertion, that a child might be produced within six months aiter conception, capable of living. I say, the greater weight of evidence went to support this rien, biti, among about sixteen eminent accoucheurs examined, it was very remarkable what a diversity of opinion was elicited. 'The shortest period of yestation allowed by any of the witnesses for the jroduction of a viable child, was five calendar months and a half, but the celebrated Dr. Hamilton, who had been a lecturer on midwifery for half a century, declared that he had never known a child to be reared after a shorter period of gestation than seven calendar months, and in his opinion that was the limit of a viable gestation. In this opinion he was also supported by Dr. W. Campbell and others. It is evident, therefore, that on so important a point, and where opinions are so conflicting, every well-ascertained fact is valuable, and I will therefore give the following case in the exact words of the patient herself, leaving it to the profession to decide how far the point in question is to be considered as clearly proved, that the conception did take place at the time that the patient states, and in consequence that the child was, bon $\vec{a}$ fide, the produce of a six months' conception.

\section{"June 25, 1841.}

“ My Dear Sir,-I assure you that I feel the most perfect willingness to send you the information that you require, respecting the little delicate baby. I had expected her birth to take place the first week in April, and believed that to be the earliest time at which it ought to happen. She was born on the 11th of January, and her appearance satisfied me that I had not been mistaken. I have had a seven months' child before, but this little creature was evidently much more premature than the other. I think you saw her when a very little growth had taken place; she had for ten days her eyes fast closed, and the nails both on her fingers and toes were only half formed; for two days she was unable to swallow, and for weeks she could only take a few drops at a time, with intervals of eight, twelve, and sometimes tiventy-four hours of apparently sound sleep, from which we could not rouse her; and if food (that is milk) was put into her mouth during this sleep, it invariably ran out again, and she seemed to be without the power of swallowing. While this state of things lasted, the baby wasted away till reduced to a skeleton, and we thought every day that the bones would have pierced through the skin. At the end of ten weeks the sleeps became shorter, she took more nourishment in consequence, and began to improve. She never from her birth showed the smallest sign of suffering, never uttered the least cry, and when awaking from her long slumber, as we thought, dying from starvation, would stretch out every limb, and indeed every finger and toe, as if perfectly comfortable. I believe you are aware that she was a twin; the first born (exactly the same size as herself) died after a few hours, in consequence of injury sustained in the birth. I hope I shall have mentioned all the particulars that you are desirous to know, but if not, pray do not hesitate to make any further inquiry. My medical attendant gave me no hope whatever of rearing the child, but I am thankful to say she is now in perfect health, having cut one tooth; backward, of course, when compared with other children, and 